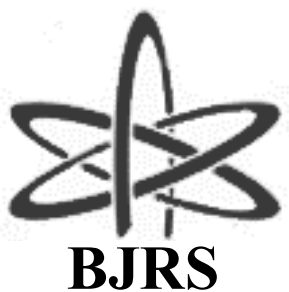

\author{
BRAZILIAN JOURNAL \\ $\mathrm{OF}$ \\ RADIATION SCIENCES \\ 06-03 (2018) 01-24
}

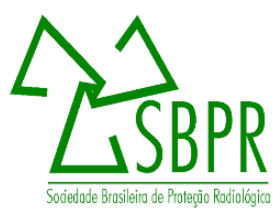

\title{
Opinião pública sobre energia nuclear enquanto sistema perito nas sociedades de risco da modernidade
}

\author{
Hansen', G.L. ; Machado², L.A.A. \\ 1 - Universidade Federal Fluminense (UFF) - CEP: 24210-470. Rua Presidente Pedreira, ${ }^{\circ}$ 62, Ingá \\ - Niterói/RJ. E-mail: gilvanluizhansen@id.uff.br \\ 2 - Comissão Nacional de Energia Nuclear (CNEN) - CEP: 22290-901. Rua General Severiano, ${ }^{\circ}$ \\ 90, Botafogo, Rio de Janeiro/RJ. E-mail: luismachado@bol.com.br
}

\section{RESUMO}

O artigo analisa a resistência da opinião pública à aceitação da energia nuclear manifestada em posicionamentos de entidades ambientalistas, confrontando estas posições com conceitos de sociedade de risco, de Ulrich Beck; de confiança/desconfiança em sistemas peritos, de Anthony Giddens; e com a necessidade de transparência para deliberar sobre políticas públicas, como defende Jürgen Habermas. Nos dias atuais, parece faltar a visão de que a sociedade precisa conviver com riscos, com sistemas peritos, e que é preciso transparência no debate público para escolha racional dos riscos a correr e dos sistemas nos quais confiar. $O$ artigo aborda o tema com o método científico hipotético indutivo, de amplo uso nas ciências sociais, e que melhor possibilita analisar dados estatísticos e posicionamentos institucionais em confronto com ideias do campo da sociologia.

Palavras-chave: opinião pública, sociedade de risco, tecnologia nuclear, energia nuclear e sistemas peritos.

\section{ABSTRACT}

The paper analyzes the resistance of public opinion to the acceptance of nuclear energy manifested through the position held by environmental entities, and confronts them with the concepts of risk society (by Ulrich Beck), confidence / distrust in expert systems (by Anthony Giddens) and with the transparency and deliberation necessary for public policies to be accepted by society, as defended by Jürgen Habermas. What the modern-day context seems to be lacking is the awareness that we are inevitably part of a risk society where we are surrounded by expert systems, and that we need transparency to promote the public discussions leading to reasonable choices over which systems to trust. The text dealt with these themes using the hypothetical-inductive scientific method, widely used in social sciences, being the method that best enables a analysis of statistical data and institutional positions when confronted with ideas from the field of sociology.

Keywords: public opinion, risk society, nuclear technology, nuclear energy and expert systems. 


\section{INTRODUÇÃO}

A imagem da energia nuclear parece estar imune às estatísticas e de uma forma bastante desfavorável a esta área do conhecimento. A opinião pública evidenciada em manifestações de ambientalistas tem se mostrado majoritariamente contrária a este segmento tecnológico. Esta resistência à energia nuclear ocorre, principalmente, desde a metade do século passado. Foi quando a explosão de bombas atômicas tornou mais conhecido o uso militar da energia nuclear. Mais recentemente, o acidente de Goiânia (1987) e acidentes envolvendo usinas nucleares (1986 e 2011) contribuíram para aumentar a resistência a tecnologias do setor nuclear.

Neste contexto, o medo e a rejeição às tecnologias nucleares tendem a não levar em conta de uma forma mais racional os relativamente baixos índices de acidentes e letalidade e o reduzido impacto ambiental registrados ao longo das últimas décadas. Em comparação com outras formas consagradas de produção de energia em larga escala, como os combustíveis fósseis e a hidroeletricidade, as técnicas nucleares são as que menos degradam o meio ambiente no que diz respeito ao agravamento do chamado efeito estufa [1] ${ }^{1}$. Apesar disso, o discurso de boa parte dos ambientalistas ainda permanece como forte oposição à energia nuclear, com uma argumentação mais baseada em aspectos ideológicos e políticos do que em dados técnicos e estatísticos.

$\mathrm{Na}$ primeira parte deste artigo são apresentadas, com base em pesquisa bibliográfica, as prováveis origens da imagem negativa da energia nuclear. Em seguida, é feita a contextualização do uso da energia nuclear na sociedade de risco, como o sociólogo alemão Ulrich Beck define a contemporaneidade. Também é abordada a aceitação pública da energia nuclear diante do conceito de confiança em sistemas peritos, evidenciado pelo sociólogo britânico Anthony Giddens. Em Habermas, foi possível encontrar elementos para análise da falta de transparência em políticas públicas que envolvem a energia nuclear, o que pode ser uma das razões da resistência percebida no meio social.

A sociedade contemporânea promove um intenso e crescente uso de tecnologias que facilitam e prolongam a vida, mas esta realidade também exige o convívio com os riscos inerentes ao aparato tecnológico. A questão central não está na inexistência de riscos. O fundamental é tê-los devidamente contabilizados, de forma a haver preparação para reagir a acidentes e reduzir as 
possibilidades de dano [2]. O devido conhecimento de riscos também é relevante para que cada grupo social possa realizar uma escolha democrática sobre conviver ou não com as possibilidades e imprevisibilidades das diferentes tecnologias. Neste ponto, a confiança na tecnologia é ponto determinante para sua aceitação na sociedade contemporânea [3].

O texto confronta esta realidade contemporânea, onde existe uma sociedade de risco e a necessidade de sistemas peritos, com discursos ambientalistas como os do Greenpeace, que há décadas exerce forte oposição à energia nuclear. Também são abordadas as opiniões de ambientalistas mundialmente conhecidos, que passaram de opositores a defensores da energia nuclear, como Patrick Moore e James Lovelock². Para o caso específico do Brasil, é analisado o discurso ambientalista de oposição à energia nuclear refletido no Mapa de Conflitos Envolvendo Injustiça Ambiental e Saúde no Brasil. O material foi elaborado pela Fiocruz e pela organização não governamental Fase, com apoio do Ministério da Saúde.

Estas posições foram confrontadas com os pressupostos de sustentabilidade estabelecidos nos textos finais da Conferência das Nações Unidas sobre Meio Ambiente e Desenvolvimento (Eco 92) e da Conferência das Nações Unidas Sobre Desenvolvimento Sustentável (Rio+20). Estes eventos ocorreram, respectivamente, em 1992 e 2012, no Rio de Janeiro. Assim, foi possível analisar a oposição à energia nuclear resultante da falta de confiança gerada por riscos mal avaliados e políticas públicas pouco transparentes dentro de uma sociedade que precisa, constantemente, escolher seus riscos.

\section{METODOLOGIA}

$\mathrm{O}$ artigo foi produzido com método científico hipotético indutivo, bastante adequado a pesquisas na área das ciências sociais. A coleta de dados ocorreu em documentos institucionais nacionais e internacionais indicativos dos riscos de diferentes tecnologias em nossa sociedade, com particular atenção à tecnologia nuclear. Registros de veículos de comunicação social (jornais e revistas) possibilitaram análises sobre o conteúdo de manifestações de ambientalistas e entidades ambientais sobre a energia nuclear. Através de pesquisa bibliográfica, estes dados e informações foram confrontados com teorias e opiniões sociológicas sobre riscos tecnológicos nas sociedades 
modernas. A pesquisa bibliográfica também deu sustentação teórica ao argumento da necessidade de diálogo e transparência na escolha e aplicação destas tecnologias.

A opção pelo método hipotético indutivo ocorreu por ser este o que melhor possibilita uma análise sociológica baseada em dados estatísticos e posicionamentos institucionais quando confrontados com ideias do campo da sociologia. Segundo Lakatos e Marconi, com tal método "partindo de dados particulares, suficientemente constatados, infere-se uma verdade geral ou universal, não contida nas partes examinadas. Portanto, o objetivo dos argumentos indutivos é levar a conclusões cujo conteúdo é muito mais amplo do que o das premissas nas quais se basearam" [4].

\section{RESULTADOS E DISCUSSÕES}

\section{1 - A militarização da energia nuclear: um mau começo}

O que pesa fortemente contra a energia nuclear é sua intensa associação com morte e destruição, que pode ter sua origem explicada pela forma impactante e negativa como foi apresentada ao mundo. Até a ocorrência das explosões em Hiroshima e Nagasaki, em 1945, a energia nuclear era pouco conhecida da população em geral. Tratava-se de assunto de cientistas em avançadas pesquisas, tema de círculos acadêmicos e ambientes de laboratórios sofisticados.

Com as explosões atômicas, a apresentação da energia nuclear ao grande público não foi das melhores. O mundo passou a falar e a prestar atenção naquela nova energia após a destruição de cidades inteiras. Houve perplexidade com a morte de milhares de pessoas em poucos segundos e as contundentes sequelas nos corpos de outros milhares de vítimas sobreviventes, as doenças que seguiram sem cura por décadas e atingiram também novas gerações. À época, eram pouco conhecidos os efeitos das radiações ionizantes ${ }^{3}$.

Entre as situações polêmicas que se consolidaram desde então, firmou-se um medo consistente e abrangente de algo com tamanho poder de destruição, que seria capaz de acabar com o mundo que conhecemos e extinguir a população do planeta. Formou-se o que se convencionou chamar de "Síndrome de Hiroshima". A expressão designa o pavor inconsciente e irracional a uma tecnologia 
que, como qualquer outra, não é mais que uma ferramenta a ter o bom ou mau uso determinado unicamente pelas mãos de quem a opera.

A energia nuclear passou a despertar sentimentos de temor que se aproximavam do pânico. Sem cheiro, sem cor, sem forma definida e possível mensageira da tragédia humana, passou a integrar o imaginário popular como alguma forma de assombração. Nas palavras do sociólogo alemão Ulrich Beck, "somos perseguidos até nos sonhos pelos temores do holocausto nuclear" [2]

Acidentes como os de Chernobyl (1986), Goiânia (1987) e Fukushima (2011) reforçaram este imaginário sombrio. Faz-se, portanto, necessária uma breve análise do que significaram estes últimos acontecimentos. Nos dois primeiros casos, Chernobyl e Goiânia, o erro humano foi responsável pelas fatalidades. O mais recente, Fukushima, teve como causa um desastre natural de grandes proporções que devastou um território considerável do Japão.

\section{2 - Chernobyl: desligamento dos sistemas de segurança}

O acidente de Chernobyl aconteceu no dia 25 de abril de 1986, na cidade de Pripyat, na Ucrânia, país que à época integrava a União das Repúblicas Socialistas Soviéticas (URSS), extinta em 1991. O governo soviético, após um primeiro momento de negação, reconheceu ter havido um acidente nuclear, cujos indícios foram percebidos em países vizinhos. No dia 27 de abril, na Suécia, aparelhos detectores acusaram níveis anormais de radiação. Situações semelhantes foram registradas em seguida na Finlândia, Noruega, Dinamarca e em outras nações próximas.

As evidências obrigaram os soviéticos a reconhecer o acidente, que ocorreu na unidade 4 da Central Nuclear de Chernobyl. O sistema automático de controle da usina foi desligado para realização de um teste da estrutura de refrigeração do núcleo do reator. Assim, com o reator controlado manualmente, abriu-se a possibilidade de erro humano. Entre as diversas falhas de procedimento constatadas posteriormente, inclui-se o desligamento de três sistemas de segurança. $\mathrm{O}$ resultado foi o excesso de pressão interna no reator e a consequente explosão de sua estrutura de blindagem, liberando radiação para o meio ambiente [5].

XAVIER et al registram que 50 trabalhadores e bombeiros que atenderam a situação de emergência morreram nos primeiros meses seguintes ao acontecimento. Conforme os autores, estimativas realizadas 19 anos após o acidente indicaram, entre as várias consequências, que quatro 
mil crianças e adolescentes contraíram câncer de tireoide devido à ingestão de alimentos contaminados pela radiação. Destes, 15 morreram. Os autores apontam que quatro mil mortes poderão ser atribuídas ao acidente [5].

\section{3 - Goiânia: fascínio do pó azul brilhante}

O acidente de Goiânia, capital do estado de Goiás, ocorreu no ano seguinte ao de Chernobyl. Em setembro de 1987, catadores de metal retiraram de uma clínica abandonada um equipamento desativado de radioterapia, destinado ao tratamento do câncer. O aparelho, que tinha como fonte de radiação uma cápsula contendo césio-137 em forma de pó, foi levado para um ferro-velho e desmanchado. A cápsula foi rompida e seu pó brilhante virou motivo de fascínio e curiosidade. Rapidamente, o material radioativo foi espalhado pelas pessoas que tiveram contato.

As investigações policiais não apontam com precisão a data em que houve o roubo do equipamento e o rompimento da cápsula de césio. O problema veio à tona no final de setembro de 1987, quando sintomas dos efeitos da radiação começaram a aparecer em algumas pessoas que procuraram atendimento médico. Surgiu a suspeita de tratar-se de contaminação por material radioativo, o que levou ao acionamento de profissionais que utilizaram detectores de radiação e confirmaram a presença de césio-137 em diferentes pontos da cidade, em pessoas, animais, plantas, objetos móveis e imóveis.

Em razão da contaminação com césio-137, 112.800 pessoas foram monitoradas, sendo que 249 apresentaram níveis de radiação acima do normal, com contaminações radioativas externas ou internas. Dos contaminados, 20 foram hospitalizados. Destes, quatro morreram nas primeiras semanas seguintes ao acidente. [6].

\section{4 - Fukushima: imprevisibilidade de um fenômeno da natureza}

$\mathrm{O}$ acidente de Fukushima, o mais recente, ainda possui efeitos pouco dimensionados. Em 11 de março de 2011, a Central Nuclear Fukushima Daiichi, localizada no Nordeste do Japão, foi atingida por um tsunami, onda de grandes proporções formada a partir de um tremor de terra no Oceano Pacífico. Além das significativas consequências, como mortes e destruição em toda a região 
Nordeste do país, o desastre natural provocou graves danos para quatro dos seis reatores da central nuclear localizada em Fukushima.

Entre os problemas registrados, o tsunami afetou os geradores elétricos que faziam parte da estrutura de resfriamento de emergência dos reatores da Central. A consequência foi o superaquecimento dos reatores, causando a liberação de material radioativo para a atmosfera. Outro problema relevante foi o vazamento de água de piscinas destinadas a depósito de material radioativo.

A Agência Internacional de Energia Atômica (AIEA) monitora os desdobramentos da situação. Até o final de 2016, os relatórios da AIEA não apontaram mortes ou feridos graves em razão dos efeitos da radiação em Fukushima. Os relatos mais relevantes dizem respeito a doses elevadas de radiação a que foram expostos trabalhadores da empresa responsável pelos reatores, a Tepco. Eles são profissionais envolvidos nos reparos necessários à Central Nuclear e foram afastados de suas funções após as exposições radioativas indevidas.

\section{5 - Risco e confiança como características das sociedades contemporâneas}

Os efeitos destes três acidentes poderiam ser analisados também quanto a impactos no meio ambiente, consequência na economia das regiões atingidas, entre outros aspectos. Optou-se neste artigo por apresentar os danos diretamente relativos a pessoas: número de mortos, feridos e portadores de doenças. Este critério de escolha foi adotado por dois motivos centrais. Primeiro, pelo fato de o discurso antinuclear predominante estar centrado na visão de uma energia nuclear como mensageira da morte e da desgraça humana [2]. A segunda razão diz respeito à possibilidade de melhor comparar os riscos e efeitos nocivos da energia nuclear com os de outras tecnologias amplamente utilizadas nas sociedades atuais. Estas tecnologias de aceitação pacificada são, em geral, aquelas nas quais a sociedade aprendeu a confiar [3].

O uso de automóveis encaixa-se bem neste raciocínio. Ambientalistas possuem carros, o Greenpeace também tem os seus veículos e outras organizações e profissionais que lutam em defesa do meio ambiente igualmente os utilizam. Ninguém imagina campanhas, protestos ou algum tipo de ação querendo banir o uso de veículos automotores. O que se vê é um esforço por um uso racional dos automóveis, pelo desenvolvimento de tecnologias menos poluentes e pela adoção de um 
comportamento civilizado ao volante. No entanto, os acidentes de trânsito foram responsáveis em 2010 por um total de 40.610 mortes no Brasil, conforme registrado no Sistema de Informações de Mortalidade (SIM) do Ministério da Saúde [7]. Certamente, fatalidades como estas precisam ser objetivamente analisadas para que se torne possível evitá-las.

Sobre aplicações da energia nuclear, também é possível ter uma ideia das mortes causadas por acidentes envolvendo estas tecnologias. Conforme relatado acima, em Goiânia, no ano de 1987, ocorreram quatro mortes. Em Chernobyl, no ano de 1986, há um total confirmado de 65 mortes atribuídas ao acidente e uma estimativa de que quatro mil pessoas morrerão como consequência dos efeitos das radiações liberadas [5]. Com estas estimativas, mesmo considerando algum outro caso esporádico ou até mesmo subnotificações que possam ocorrer, o uso da energia nuclear teria causado cerca de quatro mil mortes nas últimas quatro décadas, o que inclui o período que vai de 1986 a 2016.

Enquanto isso, o trânsito no Brasil causou a morte de mais de 40 mil pessoas em 2010. Por mais frio que seja um comparativo de mortalidade e guardadas as devidas diferenças entre um exemplo e outro, os dados são reveladores e contundentes. Em apenas um ano, em um único país, os automóveis causaram um número de mortes cerca de dez vezes maior do que a estimativa mais pessimista de vítimas fatais de acidentes com a energia nuclear em todo o mundo ao longo de 40 anos. Mesmo considerando possíveis imprecisões dos dados, é bastante considerável a diferença nas dimensões de fatalidade entre os segmentos tecnológicos referidos acima.

$\mathrm{O}$ recurso às estatísticas configura um instrumento de análise bastante interessante para as "sociedades de risco" contemporâneas, nas quais os benefícios e os perigos das tecnologias tornamse objeto de debate constante. O domínio da natureza cobrou um preço do homem. Não há nada na existência humana que não traga em si uma semente de fatalidade. Como o ser humano nasce grávido da morte, de suas escolhas sairá uma maior ou menor possibilidade de que isso ocorra de uma forma pouco natural. O próprio viver e estar na natureza já é suficiente para estar em risco. Escolher o modo de viver é também escolher os riscos a correr. Assim, Beck afasta-se de uma visão utópica da ausência de riscos. Para o autor, o que de melhor pode ser feito é ter o risco conhecido e devidamente contabilizado, de forma que a sociedade possa compreendê-lo e, com isso, fazer uma análise crítica sobre os riscos que precisa ou escolhe correr $[2]^{5}$. 
O que Beck sustenta é que o risco seja "destacado e iluminado", ou seja, que venha à tona e possa ser enfrentado, previsto e, na ocorrência do desastre, seja possível minimizar seus efeitos. Desta forma, as escolhas seriam pautadas não pela existência ou ausência do risco, mas sim por sua análise concreta e fundamentada. Outro ponto de destaque no pensamento do autor é a busca pela submissão do risco às "análises críticas da sociedade". Isso encaminha a discussão para a necessidade de se promover um debate democrático em torno das decisões sobre os riscos a correr. Assim, é necessário respeitar sociedades que, conscientes do maior ou menor risco de suas escolhas, optem por medidas que fujam à lógica estatística e científica. Esse é o caso, por exemplo, do Governo da Alemanha, que após o acidente de Fukushima, em março de 2011, anunciou um plano de longo prazo para o desligamento gradual das usinas nucleares em operação naquele país.

Esta atitude alemã recente parece adequada à análise do lapso de confiança que recai sobre a energia nuclear. Giddens refere-se a "pontos de acesso" como momentos ou lugares em que uma tecnologia ou seus peritos e representantes se conectam com a população leiga. Nestes momentos, há uma maior exposição à sociedade em geral dos limites e possibilidades de uma determinada área do conhecimento [3]. Estes pontos de acesso também podem ser considerados janelas de apresentação que unem leigos e peritos para que as tecnologias sejam traduzidas para a forma de suas aplicações e riscos no dia a dia. Isso permite a quem não é perito alguma forma de avaliá-las com foco nos seus processos decisórios pessoais. A energia nuclear, neste contexto, tem como pontos de acesso mais difundidos os acidentes e usos militares causadores de morte, sofrimento e destruição. Para entender melhor isso, vale fazer uso da forma como Giddens descreve a formação da confiança em sistemas peritos na modernidade.

Para Giddens, a modernidade tem como uma de suas relevantes características o que ele denominou de "desencaixe" dos sistemas sociais. Sob esta perspectiva, as relações sociais estariam se desencaixando, ou seja, perdendo sua conexão com os contextos locais, com os pontos físicos onde as pessoas vivem e nos quais interagem de forma mais direta. Estas relações sociais estariam cada vez mais reestruturadas, segundo Giddens, "através de extensões indefinidas de tempo-espaço" [3]. Nesta reestruturação, o autor distingue dois tipos de mecanismos bastante presentes na modernidade: as fichas simbólicas e os sistemas peritos.

Fichas simbólicas são para Giddens os artifícios que possibilitam relacionamentos sociais desprovidos de interação mais profunda entre grupos ou pessoas. O dinheiro seria um exemplo, pois 
materialmente é objeto inútil à sobrevivência humana. Porém, é atribuído ao dinheiro um valor simbólico, de forma a viabilizar a sobrevivência humana através dos processos de troca nos complexos meios de produção e circulação de produtos da modernidade.

O outro mecanismo de desencaixe destacado por Giddens refere-se aos sistemas peritos, sendo este o que guarda relação mais estreita com a aceitação pública da energia nuclear. Assim como as fichas simbólicas, os sistemas peritos também são marcados por um distanciamento de seus contextos nas relações sociais entre grupos ou pessoas. Nos sistemas peritos, porém, o distanciamento se dá com forte base na confiança que uns depositam na perícia de outros.

Em um mundo com tantas e tão diversas tecnologias sendo usadas no dia a dia, conviver e fazer uso do que não se compreende é praticamente uma imposição. Isso significa que não é preciso saber construir ou consertar um carro ou um avião para que se possa usufruir de suas benesses. Também não é preciso compreender o funcionamento de uma usina nuclear para fazer uso da energia que esta estrutura pode gerar. Da mesma forma, as pessoas são examinadas por sofisticados equipamentos hospitalares e trabalham com computadores avançados baseados na confiança que têm no adequado funcionamento destes dispositivos que são, em essência, "sistemas peritos" [3] .

Para usufruir e conviver com estes sistemas peritos não é necessário conhecer e compreender como funcionam. A variedade de sistemas na sociedade tecnológica contemporânea torna até mesmo impossível uma compreensão total de tudo que se utiliza. A confiança na segurança e eficiência destes sistemas é a principal razão de sua aceitação e incorporação às rotinas da sociedade. Conforme Giddens, “(...) a natureza das instituições modernas está profundamente ligada ao mecanismo da confiança em sistemas abstratos, especialmente confiança em sistemas peritos" [3].

A confiança em sistemas peritos pode ser gerada, principalmente nos pontos de acesso, tidos por Giddens como a "conexão entre indivíduos ou coletividades leigas e os representantes de sistemas abstratos. São lugares de vulnerabilidade para os sistemas abstratos, mas também junções nas quais a confiança pode ser mantida ou reforçada" [3]. Assim, é possível identificar um momento social no qual a confiança se desenvolve. Para o autor, interessa também saber como esta confiança pode se desenvolver.

Para Giddens, a confiança em sistemas peritos da modernidade é resultado de um processo que inicia na infância, quando aprendemos a conviver e a confiar na ciência e nas tecnologias. Em 
nossas principais interações sociais da fase infantil já começamos a adquirir confiança nestes sistemas peritos. Como explica o Giddens, "o que é transmitido à criança no ensino da ciência não é apenas o conteúdo das descobertas técnicas, mas, mais importante para as atitudes sociais gerais, uma aura de respeito pelo conhecimento técnico de todos os tipos" [3].

Esse respeito pelo conhecimento técnico é genérico, abrangente, mas na fase adulta dos indivíduos costuma sofrer interferência, em razão da maturidade e maior capacidade de análise trazidas pela experiência e pela aquisição de informações. Assim, a confiança é afetada pelo que vemos, vivemos, pelas informações que recebemos e pelos discursos que assimilamos.

Giddens define confiança como um tipo de crença específica, mas difere os conceitos genéricos de crença e confiança. Crença, no seu entendimento, estaria mais ligada a uma fé no destino, em algo abstrato e, portanto, muito mais afeita aos aspectos religiosos da vida. Por outro lado, confiança requer conhecimento, análise e a consideração de riscos envolvidos [3] $]^{7}$ Em um ponto comum das análises de Giddens e Beck, é destacado que o indivíduo moderno não nega a existência de riscos e que sua tomada de decisões e os posicionamentos que adota estão baseados em uma seleção própria do que considera riscos aceitáveis [2,3]. "O que é visto como risco "aceitável" - a minimização do perigo - varia em diferentes contextos, mas é geralmente central na manutenção da confiança", afirma Giddens [3].

\section{6 - O discurso ambientalista e a ausência de argumentação técnica}

A noção da existência atual de uma sociedade de risco, defendida por Ulrich Beck, não costuma fazer parte dos discursos ambientalistas tradicionais de oposição à energia nuclear. No Brasil, seja através de instituições nacionais ou organismos internacionais com representação local, defensores das causas ambientais parecem estar indiferentes às estatísticas ou estudos científicos que embasam as recomendações do uso da energia nuclear. A motivação de suas ações está mais próxima de uma militância antinuclear, com conceitos prévios bastante consolidados e pouco receptivos a argumentos.

Uma mostra desta postura está presente em alguns pontos específicos do Mapa de Conflitos Envolvendo Injustiça Ambiental e Saúde no Brasil, material elaborado pela Fundação Oswaldo Cruz (Fiocruz) e a organização não governamental Fase, com o apoio do Ministério da Saúde. O 
Mapa de Conflitos é um levantamento que reúne cerca de 300 situações em território nacional que apresentam, segundo a publicação, "populações e grupos atingidos/as em seus territórios por projetos e políticas baseadas numa visão de desenvolvimento considerada insustentável e prejudicial à saúde por tais populações, bem como movimentos sociais e ambientalistas parceiros" [8].

Este critério de seleção não determina que o referido conflito seja resultado de uma situação real de degradação ou desrespeito a preceitos e normas de preservação do meio ambiente ou saúde de alguma população. É necessário, apenas, que seja percebido como tal. Dessa maneira, integram o Mapa de Conflitos situações não comprovadas ou até mesmo sem indícios que demonstrem os problemas apontados, bastando apenas que determinados grupos percebam a situação como inadequada.

Assim, podendo ter por referência somente uma percepção subjetiva, é possível desprezar as análises de informações, dados, estudos científicos e realidades concretas. Tal comportamento guarda alguma semelhança ao que Beck [2] criticou a respeito da irresponsabilidade no uso de aparatos tecnológicos sem vislumbrar seus efeitos de maneira mais consistente. "A primeira prioridade da curiosidade científico-tecnológica remete à utilidade produtiva, e só então, num segundo passo, e às vezes nem isto, é que se consideram também as ameaças implicadas", afirma o autor [2]. Beck se referia a novidades científicas incorporadas à vida diária sem eficazes considerações acerca de seus desdobramentos.

Algumas abordagens da energia nuclear do Mapa de Conflitos acabam concretizando uma versão às avessas da crítica de Beck. Desse modo, a falta de análise a partir de critérios técnicos objetivos não se dá sobre a incorporação, mas serve à condenação de uma tecnologia e à defesa da interrupção de seu uso. Entre os cerca de 300 pontos de conflito de temas diversos relacionados no "Mapa" certamente estão situações que merecem vir à tona e exigem ações para remediar ou interromper atos desrespeitosos a seres humanos e à natureza. O projeto tem o mérito de denunciálas e lutar por soluções. No entanto, boa parte das questões apresentadas sobre energia nuclear é pouco fundamentada e bastante ideologizada, afastando-se de um estudo técnico, imprescindível quando o assunto é tecnologia.

A página eletrônica na internet do Mapa de Conflitos oferece um mecanismo de busca. Uma pesquisa realizada com a expressão "energia nuclear" apresentou seis resultados dos chamados 
pontos de conflito, assim intitulados: a) Falta de transparência e responsabilidade sobre minério radioativo deixa população do norte do Amapá em estado de alerta; b) Exploração de Urânio no sudoeste da Bahia envolve licenciamentos obscuros, contaminação, riscos à saúde e falta de transparência na fiscalização da política e da produção nuclear brasileiras; c) Vítimas do Césio 137 até hoje lutam pelo reconhecimento pleno de seus direitos; d) Jurubatuba é considerada a área com o maior passivo ambiental da cidade de São Paulo; e) Passivo ambiental radiativo em terreno na zona sul da cidade de São Paulo; f) Radiação e extração de urânio ameaça cearenses e baianos.

Os títulos encontrados são pouco objetivos, não correspondendo aos níveis de complexidade e de amplitude exigidos pelo tema e carecendo de argumentos consistentes para suas conclusões. Neste aspecto, vale destacar que outra característica do "Mapa" é reconhecer claramente as motivações políticas e morais que possui ao abordar a energia nuclear. Isso pode ser constatado em trecho do texto que relata o conflito denominado Radiação e extração de urânio ameaça cearenses e baianos: “(...) movimentos sociais, pesquisadores e militantes que lutam contra formas de exploração nuclear no Brasil estão norteados por princípios políticos e morais relacionados ao chamado Princípio da Precaução" $[8]^{8}$. Em outros textos do Mapa que abordam os conflitos ambientais que envolvem a energia nuclear é possível perceber opiniões semelhantes. São raciocínios em torno de questões políticas, deixando em segundo plano uma avaliação técnica e mais concreta, que seria preferível quando a questão diz respeito à adequação de uso de qualquer tecnologia.

\section{7 - Greenpeace: forte oposição a usinas nucleares}

O grupo ambientalista Greenpeace atua em vários países com relevantes resultados na denúncia de degradações ambientais decorrentes das atividades de diferentes segmentos, mas sua origem está especialmente ligada à energia nuclear. A organização consolidou-se depois que um grupo de ativistas partiu, em 1971, do porto de Vancouver, no Canadá, rumo ao Polo Ártico, onde pretendia impedir os Estados Unidos de realizar testes de bombas atômicas. A missão tornou o grupo mundialmente famoso e inspirou a formação desta que é hoje uma das maiores organizações ambientalistas do mundo. 
A postura antinuclear ainda é bastante forte na instituição e não se limita às aplicações militares desta tecnologia, como de início. As críticas recaem também sobre os usos pacíficos. No Brasil, país que tem previsão constitucional que determina um uso estritamente pacífico da energia nuclear, o Greenpeace marca sua discordância especialmente às usinas nucleares destinadas à geração de eletricidade. Documentos com este conteúdo podem ser encontrados na internet, na página eletrônica da instituição. Entre eles, há um texto que indica claramente esta oposição já no título: Uma energia cara e perigosa [9]. O texto inicia defendendo que "produzir energia nuclear continua sendo um problema" [9]. Em seguida, apresenta uma argumentação mais retórica e pouco objetiva, sem apoio em estudos estatísticos e análises técnicas: "Anualmente, diversos acidentes são registrados ao redor do mundo. Desde a extração, até o transporte e descarte do material radioativo, a população está exposta aos riscos de doenças fatais" [9]. Tal comentário poderia recair sobre quase tudo em uma vida urbana moderna. Riscos de doenças fatais e ocorrência de diversos acidentes são registrados na indústria do petróleo, na geração e consumo de eletricidade de diferentes fontes, no uso de automóveis, na alimentação com aditivos químicos e defensivos agrícolas, na construção civil. Enfim, as pessoas vivem num mundo cercado pelas ameaças que construíram. A postura recomendada por Beck [2] não é destruir tudo e recomeçar do zero, mas conhecer, contabilizar e administrar riscos.

Em outro trecho do texto, o Greenpeace afirma, a respeito da cadeia produtiva necessária ao funcionamento de uma usina nuclear, que "em todas essas etapas, há a possibilidade de ocorrer um acidente, contaminando água, solo, ar, além de pessoas e animais, e ainda não foi encontrado um destino seguro e permanente para esse lixo" [9]. Novamente, muitos objetos elaborados em nome do conforto e da praticidade desejadas pelas sociedades consumistas contemporâneas entrariam no mesmo raciocínio: carros, geladeiras, aparelhos de televisão, computadores, celulares, tablets, baterias, o asfalto das ruas, embalagens plásticas, fios elétricos que abastecem residências e empresas. São alguns produtos, entre centenas presentes no dia a dia dos cidadãos, que resultam de complexos processos e engrenagens produtivas, ao longo dos quais existem os riscos inerentes a qualquer atividade humana e resíduos gerados ainda sem solução definitiva.

Em relação às usinas nucleares, no documento citado o Greenpeace defende: "a) Fim da expansão do programa nuclear brasileiro; b) Suspensão da exploração de minério radioativo; c) Não construção da usina nuclear Angra 3; d) Investimento em geração de energias renováveis" [9]. A 
parte final do texto apresenta uma ressalva, pois recomenda a continuidade do uso da energia nuclear na área médica.

\section{8 - Um discurso ambientalista pró-nuclear}

O posicionamento do Greenpeace a respeito da energia nuclear e o apontado no Mapa de Conflitos Ambientais estão longe de ser uma unanimidade entre os ecologistas. Nomes conhecidos e respeitados na militância ambiental têm apresentado ideias diversas, entre eles James Lovelock e Patrick Moore. Ambos ficaram mundialmente conhecidos pela defesa das causas ambientais em diferentes locais do planeta. James Lovelock, de origem inglesa, ganhou fama com a criação da sua Teoria de Gaia, que entende o Planeta Terra como um superorganismo capaz de autorregular-se. O canadense Patrick Moore, hoje proprietário de uma empresa de consultoria na área de sustentabilidade, foi um dos fundadores do Greenpeace. Lovelock e Moore, atualmente, discursam a favor do uso da energia nuclear, como pode ser percebido nas publicações dos veículos de imprensa.

Em uma reportagem publicada pela revista digital Planeta Sustentável, da Editora Abril, em dezembro de 2010, intitulada Patrick Moore: entusiasta da energia nuclear [10], o canadense apresenta seus argumentos a favor das tecnologias do setor. De acordo com ele, “(...) em geral, a geração hidrelétrica é a melhor forma de energia renovável, ao lado da nuclear, porque é limpa, sustentável e não custa caro" [10]. Para o ex-integrante do Greenpeace, os ambientalistas desenvolveram resistência à energia nuclear por uma associação desta tecnologia com o mau uso realizado pelos militares $[10]^{9}$. Tal posicionamento parece ser inspirado na chamada Síndrome de Hiroshima, que resulta de uma associação da energia nuclear com a ideia de morte e destruição.

Sobre a possibilidade de desastres em usinas nucleares, Moore parece manter certa sintonia com a ideia de sociedade de risco. O ambientalista afirma que, pelas estatísticas, "uma usina está entre os lugares mais seguros do mundo" [10]. Ele crítica a opção por combustíveis fósseis também por uma lógica semelhante. Enquanto nas usinas nucleares há um risco contabilizado de dano ao meio ambiente e à população, outros tipos de geração de eletricidade usadas em larga escala na atualidade não se limitam a um risco, mas acarretam um inevitável impacto. Conforme destaca Moore, "não 
poderia ocorrer desastre maior numa usina nuclear do que a poluição causada pelas usinas a carvão atuais" [10].

James Lovelock segue na mesma linha de raciocínio quanto ao baixo impacto ambiental da energia nuclear e os seus razoáveis níveis de risco. O cientista inglês sempre foi uma referência entre os ambientalistas. O respeito à natureza e a postura pacifista resultou-lhe na alcunha de Gandhi da Ciência. Hoje, Lovelock defende as usinas nucleares como alternativa ambientalmente correta, divulgando suas opiniões publicamente. "A energia nuclear é limpa e não provoca aquecimento", afirma [11]. Em entrevista concedida à revista Superinteressante, da editora Abril, em dezembro de 2004, Lovelock teve a alcunha original adaptada para Gandhi Nuclear.

Assim como Beck [2], Lovelock percebe a visão da população sobre energia nuclear como algo muito próximo de um medo místico de assombrações. Segundo ele, "as pessoas sempre têm medo de algo. Antes, eram fantasmas e vampiros. Hoje, energia nuclear. A oposição baseia-se numa ficção hollywoodiana, na mídia e em lobbies do movimento verde" [11]. O autor ressalta o quanto os ambientalistas estão equivocados ao condenarem a energia nuclear, que deveria ser vista, na opinião dele, como uma aliada na busca de um meio ambiente mais equilibrado: "Eu mesmo sou um verde, mas tento mostrar que estão errados sobre energia nuclear" [11]. Na crítica aos efeitos nocivos do uso de combustíveis fósseis para produção de energia em larga escala, Lovelock sustenta que haja a substituição desta fonte pela energia nuclear, que ele considera um processo bastante mais "natural" $[11]^{10}$.

\section{9 - Sustentabilidade}

Independente das opiniões divergentes das correntes ambientalistas, um ponto relevante é que a energia nuclear se encaixa no conceito de sustentabilidade difundido pela Organização das Nações Unidas (ONU) e tem seu emprego apoiado por este organismo internacional. Em 1957, inspirada em um programa denominado Átomos para a Paz, a ONU criou a Agência Internacional de Energia Atômica (AIEA) para combater o uso militar desta energia e promover suas aplicações pacíficas [12].

Atualmente, a energia nuclear não encontra oposição nem mesmo nos debates específicos sobre meio ambiente realizados pela ONU. A Conferência das Nações Unidas sobre o Ambiente Humano, 
realizada em 1972 em Estocolmo (Suécia) é um marco na história das discussões ambientais em nível internacional. Seu documento final condenou o uso da energia nuclear apenas no que diz respeito à fabricação de armas de destruição em massa $[13]^{11}$.

Em 1992, no Rio de Janeiro, ocorreu a Conferência das Nações Unidas sobre Desenvolvimento, que ficou conhecida como Eco-92. As conclusões do encontro foram reunidas na Declaração do Rio sobre Meio Ambiente e Desenvolvimento. No texto, a ideia de sustentabilidade aparece associada ao uso de novas tecnologias, a avanços científicos capazes de suprir as necessidades humanas atuais com o mínimo possível de impacto [14 $]^{12}$.

A energia nuclear apresenta algumas características que a aproximam desta ideia de inovação associada à sustentabilidade. Resultante de descobertas científicas do final do século XIX e início do século XX, a energia nuclear vem apresentando um desenvolvimento constante ao longo dos últimos anos. Um relatório publicado em 2012 pela Agência Internacional de Energia Atômica (AIEA) informa que foram registrados 435 reatores nucleares em operação em todo o mundo e outros 65 em construção [15]. No Brasil, há dois reatores nucleares produzindo eletricidade em Angra dos Reis (RJ) e um terceiro em construção na mesma cidade.

Esse quadro de expansão do uso de reatores nucleares na geração de energia elétrica foi facilitado pela melhora da imagem da energia nuclear. Para Pidgeon et al (2008) [16], o percentual de pessoas favoráveis a esta tecnologia tem aumentado, entretanto essa aprovação tem uma certa fragilidade, pois qualquer acidente, de qualquer proporção, reaquece os medos históricos da energia nuclear.

Apesar dos temores, as estatísticas são favoráveis e a energia nuclear firmou-se mundialmente como a terceira mais relevante fonte de eletricidade. Dados da International Energy Agency (IEA) referentes ao ano de 2006, apresentados no Atlas de Energia Elétrica do Brasil, publicado pela Agência Nacional de Energia Elétrica (Aneel), apontaram que o segmento nuclear registrou uma participação de 14,8\% na geração da eletricidade produzida no mundo. As hidrelétricas ficaram na segunda posição deste levantamento, com uma parcela de 16\%. Os combustíveis fósseis firmaramse com destacada liderança, sendo responsáveis por $66,9 \%$ da eletricidade mundial daquele ano, assim distribuídos: carvão - 41\%, gás natural - 20,1\% e petróleo - 5,8\% [17]. No Brasil, a participação das duas usinas nucleares na produção de eletricidade ficou, em 2011, em um percentual de $2,6 \%$. [18]. 
Um ponto importante a ressaltar é a produção de energia elétrica em escala, que vem a ser os processos que são capazes de atender à grande demanda por eletricidade existente atualmente em razão do tamanho das populações e da intensidade dos níveis de industrialização. Energias hoje consideradas limpas, como eólica e solar, não dão conta de atender a estas necessidades em escala, sendo bastante eficazes como elementos complementares da matriz energética. O mundo ainda é bastante dependente de energia nuclear, das hidrelétricas e dos combustíveis fósseis. Entre estas fontes, a energia nuclear resulta em menor impacto ambiental, principalmente no que diz respeito às emissões de dióxido de carbono $\left(\mathrm{CO}^{2}\right)$, apontado como maior responsável pelo efeito estufa. No Atlas da Energia Elétrica do Brasil, a Agência Nacional de Energia Elétrica considera que esta característica da energia nuclear já está contribuindo para reduzir a resistência a seu uso [17] ${ }^{13}$.

Neste contexto, a energia nuclear atende aos preceitos de sustentabilidade. Entre eles, os previstos em um dos mais recentes documentos da ONU sobre questões ambientais: O Futuro que Nós Queremos. Trata-se da declaração final da Conferência das Nações Unidas sobre Desenvolvimento Sustentável, a Rio + 20, realizada em 2012 no Rio de Janeiro. Sem discriminar fontes, o texto destaca a importância da geração da energia na promoção da dignidade humana $[19]^{14}$.

$\mathrm{O}$ documento em nenhum ponto desqualifica a energia nuclear. Ao contrário, destaca a importância da incorporação de novas tecnologias com baixo impacto ambiental, a preocupação com as emissões de $\mathrm{CO}^{2}$, a necessidade de atender a demanda por energia de populações menos favorecidas. O conteúdo não aponta preferência específica por uma ou outra tecnologia de geração de energia, mas as características relacionadas encaixam-se ao potencial e perfil da energia nuclear $[19]^{15}$. Além de incentivar o uso de tecnologias avançadas, o texto chega a apontar as características dos avanços que busca, novamente aproximando-se da energia nuclear: "Reconhecemos a importância de se fazer um uso mais eficiente da energia e de aumentar a proporção de energia renovável limpa, de tecnologias menos poluentes e de técnicas de elevado rendimento energético, para atingir o desenvolvimento sustentável, inclusive para combater as alterações climáticas" [19].

\subsection{0 - Sistemas peritos, interesses econômico-políticos e desconfiança social}


Como expusemos até aqui, existem argumentos técnicos que apontam para a segurança e a importância estratégica da energia nuclear ao funcionamento das cidades em cenários contemporâneos.

Entretanto, além do desconhecimento técnico presente em algumas posições desfavoráveis à energia nuclear manifestadas pela opinião pública, outro fator que parece influenciar decisivamente é a desconfiança oriunda das faces visíveis de sistemas peritos que compõem a sociedade e que interferem nas decisões e procedimentos atinentes à energia nuclear. Dentre estes agentes que são faces visíveis de sistemas peritos, encontram-se as autoridades políticas ligadas a governos e instituições da administração pública, além de representantes de corporações empresariais e financeiras.

Os agentes supracitados são portadores de interesses econômico-políticos nem sempre tornados explícitos à opinião pública e agem estrategicamente junto aos governos e às instituições no sentido de fazer valer interesses privados, vinculados ao horizonte do chamado poder social [20]. E essas condutas afetam diferentes segmentos da vida em sociedade (educação, saúde, finanças, indústria, agricultura).

Ora, tais agentes se mostram influentes sobre as instituições sociais e interferem em políticas públicas, com efeitos muitas vezes danosos e prejudiciais à própria sociedade em face de interesses privados específicos. Como não admitir ou imaginar que, sendo uma área tão delicada e pouco transparente, porque muitas vezes envolta em estratégias de segurança nacional que inviabilizam o acesso amplo a informações sobre o segmento, o setor nuclear e suas políticas também não fossem alvo de desconfiança por parte da opinião pública?

O desafio que parece se apresentar é o de analisar como é possível resgatar a confiança e reconstruir pontes capazes de viabilizar o encontro de interesses públicos com a atuação dos sistemas peritos. E se isso é possível, o caminho parece ser pelo esclarecimento da população através da construção de uma opinião pública crítica em ambientes democráticos de convivência.

\subsection{1 - A democracia deliberativa como espaço de construção da confiança e da credibilidade}


Num ambiente contemporâneo, caracterizado por sociedades complexas em suas relações e onde riscos são vivenciados e precisam ser mensurados, torna-se mister que existam espaços institucionais para o acesso às informações de forma transparente. Esta é uma condição sine qua non se pode decidir sobre os riscos e escolher aquilo que se quer para a sociedade, seja em termos de gerações presentes ou de legado às futuras gerações.

Isso, todavia, só se mostra possível em ambientes democráticos, caracterizados pela possibilidade da existência de diferentes opiniões e divergências sobre valores, argumentos e concepções de mundo. Estas divergências devem ser enfrentadas num processo social dialógico. Esta é a base, o fundamento, pois, do exercício da soberania popular, um dos princípios que norteiam a maioria dos países hoje e que se encontra positivada na Constituição brasileira de 1988. Segundo Habermas, a justificação existencial do Estado reside "na garantia de um processo inclusivo de formação da opinião e da vontade, em que cidadãos livres e iguais chegam ao acordo mútuo quanto a quais devem ser os objetivos e normas que correspondam ao interesse comum. Com isso, exige-se do cidadão republicano mais que a orientação segundo seus respectivos interesses próprios" $[21]^{16}$.

Por esta razão, a democracia se coloca como uma espécie de condição de possibilidade de realização da sociabilidade. Não se trata de uma sociabilidade qualquer, mas daquela que seja viabilizadora do desenvolvimento sustentável nos moldes contidos nos documentos da ONU, capaz de garantir qualidade de vida, justiça e paz para as gerações presentes e futuras.

Com o resgate desta condição e a construção de ambientes efetivamente democráticos nas instituições sociais pelas quais as pessoas transitam, as aplicações da energia nuclear, assim como outras questões que são objeto de políticas públicas, poderão ser melhor conhecidas, debatidas e avaliadas. Este é o caminho para que uma cidadania participativa, desenvolvida em democracia deliberativa, confira legitimidade às decisões tomadas com base numa opinião pública crítica e razoavelmente esclarecida.

\section{CONCLUSÕES}


A tecnologia nuclear, como qualquer forma de domínio da natureza criada pelo homem, traz em si riscos e benefícios. Nas sociedades modernas, não há a opção de viver sem riscos, mas sim a de escolher os riscos. Parte da desfavorável imagem da energia nuclear junto à opinião pública e da resistência que enfrenta hoje está baseada em posicionamentos de inspiração predominantemente política e moral e não tanto em questões de ordem técnica, como seria mais adequado à análise de uma tecnologia. A origem desta forte condenação à energia nuclear encontra-se, provavelmente, na forma trágica como se tornou conhecida mundialmente. Experiências negativas em "pontos de acesso", onde o leigo e o perito se aproximam, têm o potencial de diminuir a confiança dos indivíduos em determinadas áreas do conhecimento.

As bombas lançadas na Segunda Guerra sobre território japonês certamente não configuraram uma boa forma de mostrar ao mundo a energia nuclear, tema que até então era mais restrito aos ambientes de pesquisa. $\mathrm{O}$ uso militar da tecnologia causou intensa associação com a ideia de morte e destruição. Ainda hoje, medo e desconfiança permeiam os debates que envolvem mesmo os usos pacíficos desta energia.

Se o mundo tivesse conhecido a eletricidade através da agonizante imagem de um condenado à morte retorcendo-se na cadeira elétrica, talvez fosse possível entender a dimensão dos efeitos negativos de um mau começo. No entanto, o uso da energia elétrica trouxe a magia da lâmpada e abriu um leque de aplicações, mais tarde ampliado para uma infinidade de áreas onde hoje a eletricidade é utilizada na vida contemporânea.

A energia nuclear, se desconectada dos conceitos negativos aos quais está amarrada por razões históricas, políticas e morais, iguala-se do ponto de vista técnico a outros processos da atualidade. Sua utilização traz inúmeras possibilidades, mas também oferece riscos, que devem ser conhecidos e contabilizados para que possam ser reduzidos e para que haja preparo para lidar com as ocorrências indesejadas. Esta é a postura que a sociedade costuma ter diante do enorme aparato tecnológico que cerca a vida contemporânea. A energia nuclear, pelo relativamente baixo índice de acidentes, danos e vítimas, e por sua característica de tecnologia limpa e de baixo impacto ambiental, precisa ser melhor avaliada junto à opinião pública no que diz respeito a sua conveniência como saída sustentável para o atendimento às atuais exigências de consumo energético. 
Mas, para que isso ocorra, faz-se presente e provocador o desafio de construir instituições sociais com cultura democrática e inclusiva, onde a transparência de informações e a capacidade de argumentação, de crítica e de autocrítica, de diálogo alicerçado em racionalidade comunicativa, sejam elementos corriqueiros e impulsionadores de práticas discursivas de legitimação das decisões, das ações institucionais e das políticas públicas que a elas se conectam.

\section{REFERÊNCIAS}

[ 1 ] ROSA, Luiz Pinguelli. Geração hidrelétrica, termelétrica e nuclear (2007). Revista Estudos Avançados, abr. 2007, São Paulo, vol. 21, nº 59, p. 39-58. Disponível em http://www.scielo.br/scielo.php?script=sci_arttext\&pid=S0103-40142007000100005. Acesso em 21 dez. 2016.

[ 2 ] BECK, Ulrich. Sociedade de risco: rumo a uma outra modernidade. São Paulo: Editora 34, 2010.

[ 3 ] GIDDENS, Anthony. As Consequências da Modernidade. São Paulo: Editora Unesp, 1991.

[ 4 ] LAKATOS, Eva Maria; MARCONI, Marina de Andrade. Fundamentos de metodologia científica. 5. ed. São Paulo: Atlas, 2003.

[ 5 ] XAVIER, Ana Maria; GAIDANO, Elena; MORO, José Tullio; HEILBRON, Paulo Fernando. Princípios Básicos de Segurança e Proteção Radiológica. 3 ed. Rio de Janeiro: CNEN/UFRGS, 2010. 249 p.

[ 6 ] IAEA (International Atomic Energy Agency). The Radiological Accident in Goiânia. Viena: IAEA, 1988.

[ 7 ] MINISTÉRIO DA SAÚDE. Trânsito é responsável por mais de 40 mil mortes no Brasil. Portal da Saúde, 2011. Disponível em http://portalsaude.saude.gov.br/index.php/cidadao/principal/agencia-saude/noticias-anterioresagencia-saude/900-transito-e-responsavel-por-mais-de-40-mil-mortes-no-brasil.. Acesso em 19 dez. 2016.

[ 8 ] FIOCRUZ; FASE; MINISTÉRIO DA SAÚDE. Mapa de conflitos envolvendo injustiça ambiental e Saúde no Brasil. Disponível em http://www.conflitoambiental.icict.fiocruz.br/. Acesso em 19 dez. 2016.

[ 9 ] GREENPEACE. Uma energia cara e perigosa. Disponível em https://www.greenpeace.org/archive-brasil/pt/O-que-fazemos/Nuclear . Acesso em 28 dez. 2016. 
[ 10 ] MOORE, Patrick. Patrick Moore: entusiasta da energia nuclear. Revista Digital Planeta Sustentável, Editora Abril, 2010. Disponível em:

http://planetasustentavel.abril.com.br/noticia/desenvolvimento/entrevista-patrick-moorefundadores-greenpeace-616107.shtml. Acesso em 19 dez. 2016. Entrevista concedida a Roberto Machado.

[ 11 ] LOVELOCK, James. O Gandhi Nuclear. Revista Superinteressante. Editora Abril, 2004. Disponível em http://super.abril.com.br/ecologia/gandhi-nuclear-444990.shtml. Acesso em 19 dez. 2016. Entrevista concedida a Eduardo Sklarz.

[ 12 ] IAEA (International Atomic Energy Agency). History. Disponível em: https://www.iaea.org/about/overview/history. Acesso: 9 jul. 2018.

[ 13 ] CONFERÊNCIA das Nações Unidas sobre o Meio Ambiente Humano. Declaração de Estocolmo. ONU, 1972. Disponível em http://www.onu.org.br/rio20/img/2012/01/estocolmo1972.pdf. Acesso em 19 dez. 2016.

[ 14 ] CONFERÊNCIA das Nações Unidas sobre Desenvolvimento (Rio 92). Declaração do Rio sobre Meio Ambiente e Desenvolvimento. ONU, 1992. Disponível em http://www.onu.org.br/rio20/img/2012/01/rio92.pdf. Acesso em 19 dez. 2016.

[ 15 ] IAEA (International Atomic Energy Agency) Nuclear Power Reactors in The World. Viena: IAEA, 2012.

[ 16 ] PIDGEON, Nick, F, LORENZONI, I, e POORTINGA, W. Climate change or nuclear power-No thanks! A quantitative study of public perceptions and risk framing in Britain. Global Environmental Change, v. 18, n.1, p. 69-85, 2008.

[ 17 ] ANEEL (Agência Nacional de Energia Elétrica). Atlas de Energia Elétrica do Brasil. Brasília: Aneel, 2008.

[ 18 ] EPE (Empresa de Pesquisa Energética). Balanço Energético Nacional 2012. Rio de Janeiro: EPE, 2012.

[ 19 ] CONFERÊNCIA das Nações Unidas sobre Desenvolvimento Sustentável (Rio + 20). O Futuro Que Queremos. Florianópolis: UFSC, 2012. Disponível em: http://riomais20sc.ufsc.br/files/2012/07/O-Futuro-que-queremos1.pdf. Acesso em 19 dez. 2016.

[ 20 ] HABERMAS, Jürgen. Direito e democracia: entre facticidade e validade. Tradução de Flávio Beno Siebeneichler. Rio de Janeiro: Tempo Brasileiro, 1992. v. 1.

[ 21 ] HABERMAS, Jürgen. A inclusão do outro: estudos de teoria política. Tradução de George Sperber e Paulo Astor Soethe. São Paulo: Loyola, 2002. 
1 Em artigo intitulado "Geração Hidrelétrica, termelétrica e nuclear", o físico Luiz Pinguelli Rosa, professor da Coppe/UFRJ, membro do Fórum Brasileiro de Mudança Climática e um especialista na área de energia, afirma que "Do ponto de vista ambiental, a energia nuclear tem hoje a vantagem de não emitir gases do efeito estufa. As termelétricas emitem muito dióxido de carbono usando combustíveis fósseis como carvão, petróleo e gás natural. As hidrelétricas, embora se considerassem suas emissões desprezíveis, estudos realizados nos reservatórios pelo meu grupo de pesquisas no Instituto Virtual Internacional de Mudanças Globais da Coppe-UFRJ, em cooperação com o grupo de limnologia de São Carlos, mostraram que elas emitem metano e dióxido de carbono, em geral muito menos de que as termelétricas" [1], p. 49.

2 James Lovelock e Patrick Moore já foram ícones ambientalistas e ficaram conhecidos como fervorosos ativistas das causas ambientais em nível mundial. James Lovelock, de origem inglesa, ficou famoso por ter criado a chamada Teoria de Gaia, que entende o planeta Terra como um imenso superorganismo. O canadense Patrick More foi um dos fundadores do Greenpeace.

3 Tipo de radiação liberada em explosões nucleares que pode ter consequências sobre a saúde humana, entre outras várias características desta energia.

4 “(...) as ameaças da civilização fazem surgir uma espécie de novo "reino das trevas”, comparável com os deuses e demônios da Antiguidade, que se ocultavam por traz do mundo visível e ameaçavam a vida humana no planeta. Hoje em dia, não nos comunicamos mais com os espíritos que se escondem nas coisas, mas nos vemos expostos a "irradiações", ingerimos "teores tóxicos" e somos perseguidos até nos sonhos pelos temores do "holocausto nuclear" [2], p.89.

5 "O acúmulo de ameaças protocoladas pelas ciências naturais e geradas pelo processo de modernização, configurado e dirigido econômico-tecnologicamente, pode, ao ser de tal forma destacado e iluminado, pelo descaso das zonas tabus surgidas com a politização, acabar conferindo à crítica científica uma nova qualidade. Fórmulas químicas, biológicas, físicas, e medicinais ameaçadoras convertem-se furtivamente em "premissas axiológicas objetivas" para análises críticas da sociedade". [2], p.101.

6 "Por sistemas peritos quero me referir a sistemas de excelência técnica ou competência profissional que organizam grandes áreas dos ambientes material e social em que vivemos hoje. A maioria das pessoas leigas consulta "profissionais" - advogados, arquitetos, médicos etc. - apenas de modo periódico ou irregular. Mas os sistemas nos quais está integrado o conhecimento dos peritos influenciam muitos aspectos do que fazemos de uma maneira contínua". [3], p.37.

7 "A confiança pode ser definida como crença na credibilidade de uma pessoa ou sistema, tendo em vista um dado conjunto de resultados ou eventos, em que essa crença expressa uma fé na probidade ou amor um do outro, ou na correção de princípios abstratos (conhecimento técnico)" [3], p.45.

8 "No entanto, atentos ao desenrolar desta atividade, movimentos sociais, pesquisadores e militantes que lutam contra formas de exploração nuclear no Brasil estão norteados por princípios políticos e morais relacionados ao chamado Princípio da Precaução. Em processos produtivos que possivelmente causem efeitos danosos e irrecuperáveis, e mesmo que tais efeitos não estejam cientifica e empiricamente provados de originarem esses danos, a intervenção mais adequada é a de recusa à continuidade do projeto para proteção das atuais e futuras gerações" [8], n.p.

9 "Nas décadas de 70 e 80, os ambientalistas fizeram a conexão entre energia nuclear e armas nucleares, ou algo do tipo, e decidiram que ela era malévola. Por causa deles é que tantas usinas termelétricas a carvão foram construídas nos Estados Unidos, China e Europa" [10], n.p.

10 "Se você olhar para o Universo, verá que sua energia natural é nuclear. Toda estrela é uma estação nuclear, inclusive o Sol. O único método anômalo de obtenção de energia é a queima de combustíveis aqui na Terra. É muito mais natural usar energia nuclear do que queimar carvão e mandar gás carbônico para a atmosfera" [11], n.p.

11 "Princípio 26 - É preciso livrar o homem e seu meio ambiente dos efeitos das armas nucleares e de todos os demais meios de destruição em massa. Os Estados devem-se esforçar para chegar logo a um acordo - nos órgãos internacionais pertinentes - sobre a eliminação e a destruição completa de tais armas" [13], n.p.

12 "Os Estados devem cooperar no fortalecimento da capacitação endógena para o desenvolvimento sustentável, mediante o aprimoramento da compreensão científica por meio do intercâmbio de conhecimentos científicos e tecnológicos, e mediante a intensificação do desenvolvimento, da adaptação, da difusão e da transferência de tecnologias, incluindo as tecnologias novas e inovadoras" [14], n.p.

13 "Além da ocorrência dos acidentes, outro fator que motivou a oposição às nucleares foi o fato de que o processo de fissão do átomo de urânio é o mesmo que dá origem à bomba atômica. Assim, o país que domina a tecnologia de processamento e transformação do minério pode utilizá-la tanto para a produção de energia elétrica quanto para fins bélicos. Nos últimos anos, porém, essa oposição tornou-se mais moderada. Lado a lado com os riscos, passaram a ser enumerados os pontos favoráveis à instalação de novas centrais. Entre eles, a disponibilidade de combustível (urânio) e a baixa emissão de dióxido de carbono (CO2) ou qualquer outro gás que contribua para o efeito estufa - o que transforma a energia nuclear em energia limpa" [17], n.p. 
14 "Reconhecemos o papel fundamental que a energia desempenha no processo de desenvolvimento, já que o acesso a serviços de energia modernos sustentáveis contribui para a erradicação da pobreza, salva vidas, melhora a saúde e atende às necessidades básicas do ser humano" [19], p. 26.

15 "Reconhecemos o papel crucial da tecnologia, bem como a importância da promoção da inovação, em particular nos países em desenvolvimento. Convidamos os governos, conforme o caso, a criar condições propícias às tecnologias, à pesquisa e desenvolvimento e às inovações que respeitem o meio ambiente, nomeadamente a serviço da economia verde no contexto do desenvolvimento sustentável e da erradicação da pobreza" [19], p. 14.

16 "A força e o poder não se originam do mercado ou do Estado, mas do poder gerado comunicativamente em meio à práxis de autodeterminação dos cidadãos do Estado e legitima-se pelo fato de defender essa mesma práxis através da institucionalização da liberdade pública. A justificação existencial do Estado não reside primeiramente na defesa dos mesmos direitos subjetivos, mas sim na garantia de um processo inclusivo de formação da opinião e da vontade, em que cidadãos livres e iguais chegam ao acordo mútuo quanto a quais devem ser os objetivos e normas que correspondam ao interesse comum. Com isso, exige-se do cidadão republicano mais que a orientação segundo seus respectivos interesses próprios" [21], p. 272-273. 